\title{
A BIBLIOTECA IMAGINÁRIA DE EDSON ROSA DA Silva: ANTIDESTINO E METAMORFOSES DE UMA REFLEXÃO DA LITERATURA
}

EDSON ROSA DA SILVA'S IMAGINARY LIBRARY: ANTI-DESTINY AND METAMORPHOSES OF A REFLECTION OF LITERATURE

\section{Rodrigo lelpo}

ORCID 0000-0002-8306-6974

Universidade Federal do Rio de Janeiro Rio de Janeiro, RJ, Brasil

\section{Resumo}

Este ensaio visa empreender uma leitura crítica do livro A reflexão da literatura: ensaios sobre literatura francesa, de Edson Rosa da Silva, que possibilite a apreensão do que poderíamos entender como o método teórico-crítico que teria balizado o trabalho do autor ao longo de sua carreira.

Palavras-chave: Edson Rosa da Silva; literatura francesa; crítica literária.

\begin{abstract}
This essay aims to conduct a critical reading of the book $A$ reflexáo da literatura: ensaios sobre literatura francesa, by Edson Rosa da Silva, which will enable the apprehension of what we could understand as the theoretical-critical method that would have guided the author's work throughout his career.
\end{abstract}

Keywords: Edson Rosa da Silva; french literature; literary criticism.

\section{Résumé}

Cet essai vise à effectuer une lecture critique du livre $A$ reflexão da literatura: ensaios sobre literatura francesa, de Edson Rosa da Silva, qui nous permet d'appréhende ce qu'on pourrait tenir pour la méthode théorique-critique qui aurait guidé le travail de l'auteur tout au long de sa carrière.

Mots-clés: Edson Rosa da Silva; littérature française; critique littéraire. 
Publicado em 2013, L'album de l'art à l'époque du musée imaginaire é o resultado de uma série de cinco conferências proferidas no museu do Louvre pelo filósofo e historiador da arte Georges Didi-Huberman em setembro daquele mesmo ano. Ao dissertar sobre o pensamento estético do escritor André Malraux, Didi-Huberman emprega nesse livro sua costumeira erudição que, ao invés de afastar o leitor, o lança num universo repleto de referências que o ajudam a traçar uma constelação ao mesmo tempo exaustiva e bastante precisa no que tange ao objeto abordado. Especificamente nessa obra, logo nas primeiras páginas, ao fazer um comentário sobre as relaçóes entre as reflexôes sobre a arte feitas por Malraux e por Walter Benjamin, Didi-Huberman nos remete, por meio de uma nota, ao artigo "La rupture de l'aura et la métamorphose de l'art. Malraux, lecteur de Benjamin". Escrito por Edson Rosa da Silva, especialista na obra de Malraux, a referência em questão expóe a impressionante penetração do trabalho deste que foi, certamente, um dos grandes estudiosos da literatura francesa no Brasil nas últimas décadas. Professor Titular de Língua e Literatura Francesa da Universidade Federal do Rio de Janeiro e pesquisador do $\mathrm{CNPq}$, Edson não teve tempo de ver publicado o livro que vinha organizando e que reúne parte qualitativamente expressiva da sua produção.

Os 14 ensaios que compóem A reflexão da literatura: ensaios sobre literatura francesa são o testemunho da capacidade multifacetada de seu autor. Divididos em dois grupos distintos, o conjunto de textos dá prova de uma carreira que soube aliar erudição e clareza, focalização da pesquisa e abertura temática, compondo um livro que pode ser pensado por uma fórmula táo curiosa quanto precisa: "elegância da simplicidade". ${ }^{1}$ Pois tanto na primeira parte, dedicada a Malraux, quanto na segunda, onde são estudados diferentes autores e obras, a economia das citaçóes, os tensionamentos entre a abstração dos conceitos e os casos concretos de sua própria experiência de leitor e amador das artes em geral permitem a Edson escrever artigos a um só tempo rigorosos teoricamente e generosos com quem deles se aproxima. Arriscaria dizer que há nisso um método que confere unidade a seu livro e que pode ser depreendido do primeiro parágrafo do último artigo de $A$ Reflexão, intitulado "As Flores do mal inspirando outras cidades": "[a]creditando que a reflexão teórica nasce sempre das obras ou é por elas provocada, agrada-me espreitar nos textos que leio ou releio o lugar onde possa encontrar um fio interessante e promissor a seguir" (SILVA, 2020, p. 153). No artigo anterior a esse, "Quando a aranha perde o fio da meada", onde também estabelece um diálogo com o livro Les derniers jours de Charles Baudelaire, de Bernard-Henri Lévy, Edson oferece outra pista que sustenta a afirmação sobre seu processo crítico ao falar da própria

1 O sintagma é utilizado por Arlete Cavaliere e Eduardo Tolentino Araújo, tradutores da peça Ivánov, de Tchékhov, para falarem da escrita do autor russo. Ver bibliografia. 
estratégia narrativa de Lévy: “(...) a voz de Baudelaire enleva e enreda Lévy que, à escuta do poeta e retomando o fio da meada, inscreve ecos e sussurros à margem do texto primeiro" (SILVA, 2020, p. 141). É por meio desse jogo de vozes que seus textos deixam entrever certo desejo de aliar os papéis de pesquisador e professor em tudo o que fazia. Textos que, ao convidarem o leitor para o concerto coral por ele criado, podem tocar tanto intelectuais experimentados quanto estudantes em início de percurso através desse gesto que parece evocar o que nos diz Roland Barthes sobre o amador: "[o] que salva do risco de recuperação teológica - por um significado - é justamente acentuar o prazer da produção, é fazer de si mesmo um produtor, isto é, um amador" (BARTHES, 2004, p. 289).

Para além dos artigos mencionados, na segunda parte de $A$ reflexão esse movimento está a serviço de um vasto campo reflexivo que aparece de modo explícito em formulaçóes teóricas como as citadas há pouco. Estas tornam manifesto o parti pris de seu autor, para quem, em diálogo com a différance derridiana, "[a]s palavras não valem mais pelo conteúdo semântico, porém por seu poder de combinação com outros significantes. Palavras não se leem apenas. Palavras se veem, se tocam, se sentem" (SILVA, 2020, p. 149). Essa afirmação aparece de diferentes maneiras em todos os artigos desse eixo do livro, começando, não por acaso, com o primeiro desses textos, no qual Edson se propóe a refletir sobre a obra de Barthes. Em "A circulação dos textos", partindo da ideia central segundo a qual "o leitor é um criador virtual” (BARTHES apud SILVA, 2020, p. 92), Edson reafirma seu método criativo ao defender que "é dessa relação que nasce a liberdade da invenção, é do reflexo dos textos que se pode vislumbrar outro texto, é das possibilidades múltiplas que o diálogo desses textos propóe que se destrói a convicção de um saber absoluto (SILVA, 2020, p. 92). E é a crítica desse tipo de saber que encontramos na leitura que ele faz de Flaubert a partir da pergunta que dá título a outro de seus artigos: "Flaubert realista?". Ao ler a obra do autor de Madame Bovary, Edson parece privilegiar A tentação de Santo Antão e Bouvard e Pécuchet como livros que permitem pensar a crítica a certo regime de verdade próprio ao que se convencionou chamar de realismo em referência a parte da produção literária no século XIX. Em sua argumentação, Edson relaciona essas obras do escritor francês com a célebre passagem da carta em que ele fala a Louise Colet sobre o seu desejo de escrever "um livro sobre o nada" (FLAUBERT apud SILVA, 2020, p. 109). Ao colocar essa trama em diálogo novamente com Barthes assim como com as reflexóes que Michel Foucault faz sobre $A$ tentação, Edson conclui:

a grande proposta do escritor situa-se, pois, no entrecruzamento de duas aspiraçôes contraditórias: a de um livro enciclopédico (o saber, a realidade, o 
mundo, tudo) e a de um livro sobre o nada, numa tentativa talvez de significar que o grau zero do conhecimento é a totalidade do saber em processo, que a escritura precede todos os livros, que a escritura só é possível no vazio que a própria escritura instala (SILVA, 2020, p. 115).

A leitura de $A$ reflexáo deixa claro que as relaçóes entre saber e processo descritas nessa passagem pautam o posicionamento teórico-crítico de seu próprio autor, repercutindo em todos os seus textos, como afirmado anteriormente. Leitor atento de Walter Benjamin, Edson parece, assim, aproximar-se das reflexóes que o filósofo alemão faz sobre o conceito de crítica de arte para os românticos alemães, crítica essa que falaria de "um desdobramento e de uma intensificação continuamente mais abrangentes das formas poéticas", entendendo-a, então, como "um processo de realização infinito" (BENJAMIN, 2002, p. 96).

É essa sensibilidade que conduz Edson a debruçar-se, em "Inventário e Imaginação: escrever / escavar o(s) espaço(s) etc", sobre as operaçóes textuais de Georges Perec, escritor que, segundo sua leitura, "Escava não só seus [das palavras] sentidos múltiplos, mas, sobretudo, os meandros de suas potencialidades criativas: pelos jogos, dos mais simples aos mais complexos, inventando uma forma ousada de dizer o cotidiano de outra forma" (SILVA, 2020, p. 129-130). Aliás, esse é um dos textos em que sobressai o seu rico diálogo com a obra benjaminiana, o que o possibilita ler o livro Espèces d'espaces na chave de uma poética do cotidiano, presente na obra de Perec, nos seguintes termos:

Daí a importância de uma reflexão que, partindo do banal, da brincadeira, do puzzle das cidades, do colorido dos mapas, da proximidade de poemas, cantigas infantis, fragmentos diversos, lhe descobre um outro sentido. Não olha para o passado como algo a ser recuperado como força original, como verdade ao pé da letra, mas quer captar-lhe o movimento contínuo da descontinuidade, o turbilhão de imagens que se sobrepóem, sobretudo no mundo moderno da tecnologia, de coisas que se desfizeram, destruíram, enterraram. Mas que estão lá, aí, aqui: trabalhando, olhando para nós, provocando nossa reflexão. Tudo por recomeçar (SILVA, 2020, p. 132-133).

A importância da presença de Benjamin para o pensamento de Edson se faz ver principalmente nos outros dois textos que completam essa segunda seçáo do seu livro. Em "A citação: o lugar da passagem (repensando com Walter Benjamin)", o autor lança sua atenção sobre o conhecido fragmento de Rua de mão única em que o filósofo alemão compara as citaçóes que faz em seus textos com "salteadores no caminho, que irrompem armados e roubam ao passante a convicção" (BENJAMIN apud SILVA, 2020, p. 99). 
Estabelecendo uma tensão reflexiva entre citar e coletar na obra de Benjamin, Edson procura pensar nesse artigo as relaçóes entre montagem, fragmento e literatura para esse pensador sui generis, tendo em vista, novamente, a crítica à possibilidade de um conhecimento total - e por isso mesmo, totalitário. Daí a centralidade da pergunta que surge no instante em que comenta as Passagens de Paris: "Como atingir a compreensão pelo viés da fragmentação e da recusa de uma sistematização?” (SILVA, 2020, p. 104).

Esse mesmo tipo de questionamento encontra-se mobilizado em "Da impossibilidade de contar e de cantar: um olhar benjaminiano sobre a literatura”. Neste, Edson parte da problematização da experiência dramatizada em ensaios como "Experiência e pobreza" e "O contador" como forma de desdobrar a seguinte afirmação a respeito do pensamento benjaminiano:

(...) sua reflexão sobre a literatura e as manifestações culturais na era da tecnologia sempre visou atingir o objeto mais amplo de uma inquiriçáo filosófica que buscasse, não o conhecimento da Verdade, mas a apreensão, de forma fragmentária, dos mais variados momentos da experiência humana (SILVA, 2020, p. 117).

Seguindo os rastros das reflexões desenvolvidas por Benjamin em torno da obra de Baudelaire, Edson reflete sobre a impossibilidade indicada no título de seu artigo a partir do deslocamento dialético ocasionado pela perda da aura da obra artística nos termos do filósofo alemão. Trata-se, desse modo, de pensar o lugar da reflexão literária benjaminiana na esteira da transição que o filósofo indica do valor de ritual para o valor de exposição das obras de arte na modernidade. Nessa operaçáo, diante da perda da experiência em sua relação com a tradição, logo, em sua dimensão coletiva (Erfahrung), a literatura é pensada a partir da experiência do choque (Erlebnis). Edson procura, assim, refletir sobre as consequências de uma criação que deveria, então, ser engendrada sob a égide de um "conceito novo e positivo de barbárie" (BENJAMIN apud SILVA, 2020, p. 118), a partir do qual tanto Benjamin quanto Baudelaire teriam procurado "tornar o objeto dialético pleno de sentidos e de contrastes, atribuindo-lhe sempre uma significação múltipla e provisória" (SILVA, 2020, p. 122).

Mas é na primeira parte do livro que o pensamento de Benjamin parece ocupar seu lugar de maior destaque. É nela que se encontram os sete ensaios sobre as reflexôes de André Malraux. Dentre estes, o primeiro retoma, justamente, o artigo citado por Didi-Huberman e aludido no início desta resenha. Nas palavras de Márcio Seligmann-Silva, que escreveu a orelha de A reflexão, esse texto pode ser considerado "o grande destaque dessa bela obra” (SELIGMANN-SILVA, 2020, Orelha do livro). Em "Walter Benjamin 
no limiar do pensamento estético de André Malraux”, Edson cartografa a influência do pensador de $A$ obra de arte na era de sua reprodutibilidade técnica e suas teorizaçôes sobre a aura - e sua perda - nas reflexôes do próprio Malraux em torno de conceitos como o de "museu imaginário" e "metamorfose". O trabalho de cotejamento ao mesmo tempo conceitual e histórico empreendido pelo artigo demonstra a importância das ideias de Benjamin sobre o impacto da reprodutibilidade técnica no advento da arte moderna para as teorizaçóes de Malraux. Assim, ao analisar o movimento de "emancipaçáo do sagrado" que Benjamin nos faz ver no deslocamento da função ritual das obras da antiguidade para a sua função de exposição na modernidade, Edson nos mostra seus desdobramentos nas investigaçóes sobre a emancipação da arte para o próprio Malraux, para quem, "[a]té o século XIX, todas as obras de arte foram a imagem de alguma coisa que existia ou não existia, antes de serem obras de arte" (MALRAUX apud SILVA, 2020, p. 15). É essa ideia que permite ao escritor francês afirmar, numa das passagens de Le musée imaginaire, que "a metamorfose mais profunda começou quando a arte já não tem outro objetivo que não fosse ela própria” (MALRAUX, 1951, p. 52). Como o texto de Edson mostra, o impacto das técnicas de reproduçáo para o campo artístico analisado por Benjamin foram cruciais para que Malraux pensasse suas relaçóes com o caráter de exposição das obras, partindo da gravura, passando pela fotografia, até chegar ao advento do cinema.

Esse tensionamento entre os dois autores também tem papel de destaque no artigo "A fotografia na reflexão de André Malraux". Aqui, Edson explora, de modo bastante produtivo, as aproximaçóes e distanciamentos entre os posicionamentos de ambos os pensadores no que tange às relaçóes entre fotografia, reprodutibilidade e arte, mostrando de que modo, para Malraux, " $\mathrm{r}$ ] evelando pela fotografia obras singulares perdidas nos museus ou em coleçóes particulares, a reprodução contribui para mudar-lhes [das artes] a função" (SILVA, 2020, p. 87). Ao acompanhar o movimento das investigaçóes de Malraux estendidas ao trabalho da câmera no cinema, Edson procura expor a maneira como o desenvolvimento dos modos de reprodução técnica teriam modulado o pensamento crítico do autor, argumentando em prol de uma permanência modificada da aura da obra de arte: "Malraux é muito perspicaz quando se recusa a apoiar a tese que condena a máquina: é capaz de prever logo os benefícios que a arte e a sociedade poderão daí tirar. Sua atitude não é nostálgica com relação ao sagrado. Sabe que cada tempo tem a sua aura" (SILVA, 2020, p. 88). A aura se deslocaria, assim, de sua ausência para sua insubmissáo, pensada no domínio das metamorfoses próprias a toda arte, a qual, com o cinema, teria entrado na era de um novo museu imaginário.

A importância do cinema e da técnica cinematográfica reaparece em "André Malraux e o cinema", onde encontramos uma extensa reflexão sobre 
as relações desta com o romance L'espoir. Segundo Edson, "a admiração de Malraux pela arte cinematográfica justifica muitas vezes, para certos críticos, não só as alusóes ao cinema no texto dos romances como também a utilização de técnicas em geral atribuídas ao cinema na estrutura narrativa" (SILVA, 2020, p. 63). Ao pensar criticamente sobre o que seria essa importação do domínio do audiovisual para a literatura e debruçar-se sobre o diálogo entre os diferentes tipos de produção artística, o artigo procura refletir sobre as complexas relaçóes entre arte e real: "[o] mundo moderno oferece um espaço propício ao diálogo das artes. Como em um grande museu. Como o 'museu imaginário', para retomarmos o conceito criado pelo próprio Malraux" (SILVA, 2020, p. 68).

Carro-chefe do pensamento malruciano, o museu imaginário é tema recorrente nessa primeira seção. Em "O museu imaginário e a difusão da cultura”, ao mapear as diferentes conformaçóes do conceito, Edson nos guia por suas "metamorfoses", fazendo-nos compreender que o mesmo " $\mathrm{t}] \mathrm{raduz}$, inicialmente, a ideia de um museu de imagens, para depois vir a significar, sobretudo, um museu do imaginário. Dois conceitos que dialogam e se completam a todo instante" (SILVA, 2020, p. 26). Mostrando-nos como, nesse museu, as obras se metamorfoseiam ao travarem relaçóes com obras distintas no tempo e no espaço de suas produçóes, o artigo nos permite compreender uma lógica da correspondência e do confronto segundo a qual a arte, "se copia de alguma forma o mundo real, não deixa sobretudo de aludir ao mundo das formas inventadas, configurando o museu e a biblioteca" (SILVA, 2020, p. 32). Essa questáo retorna em "Malraux e Picasso além das formas", onde o autor reflete sobre o diálogo entre o escritor e o pintor a partir de um ensaio que o primeiro publica sobre o segundo sob o título de La Tête de l'obissidienne. Edson procura mostrar como a ideia do confronto entre formas artísticas é pensada por Malraux - e pela leitura que este oferece do próprio Picasso - como motivador central da criação: “[o] objeto da arte não é mais o mundo: é a própria arte e seus procedimentos de criação. Suas formas escapam ao controle das convenções: nascem da confrontação e do conflito com as obras anteriores" (SILVA, 2020, p. 39).

Esse diálogo entre diferentes campos da arte é uma constante nos artigos dedicados a Malraux e permite a Edson lançar questionamentos que, para além da literatura, abrangem as artes de modo geral. Um exemplo das muitas passagens em que isso acontece encontra-se em "Da representação do horror ao vazio da representaçáo". A partir de uma leitura do livro Saturne, que Malraux dedicou ao trabalho de Goya, Edson se propóe a pensar as relaçóes entre o sagrado e a morte abordadas por Malraux na obra do pintor espanhol, estendendo-as para a arte em geral. Ao tratar dessas relaçóes, o artigo declara uma filiação de pensamento com Nietzsche e Bataille visando se afastar de uma 
concepçáo cristã do sagrado para incorporar a ideia de um "sagrado pleno, aquele que, etimologicamente, reúne puro e impuro (...)" (SILVA, 2020, p. 46). A intenção declarada do autor é, a partir desses referenciais teóricos, desenvolver "um instrumental conceitual que [lhe] permita tratar o abjeto como um cruzamento de sentidos, em que se encena um paradoxo: o do abjeto (ab-jectum), rejeitado pelo humano, mas que do humano provém. $\mathrm{O}$ abjeto é uma metáfora da repulsa / atração da morte" (SILVA, 2020, p. 46). Prescrutando essas questóes na própria ficção malruciana, Edson expande o campo de investigação para pensar o problema da representação do horror e suas relaçôes com a memória no século XX, suscitando uma reflexão éticoestética de extrema atualidade para o campo das artes: "Ainda não sei bem como elaborar essa reflexão. Mas parece-me que a forma vazia, tal qual a linguagem do silêncio, é uma forma de proteger o já desumanizado, ou pelo menos de impedir a sua nova desumanização" (SILVA, 2020, p. 53).

Abordado por outro viés, o problema da representação também ocupa lugar de destaque em "Da ilusão à alusão: o olhar do pintor e do escritor sobre a realidade". Nele, Edson, ao ler cuidadosamente os escritos de Malraux sobre as artes plásticas, coloca a seu leitor uma série de perguntas cruciais para o desenvolvimento teórico e prático da arte moderna e contemporânea:

É diante do mundo real que surge o impasse da arte: que realidade representar? Até que ponto é possível essa representação? Que faz o artista? Reproduz o mundo tal qual é ou conforme o que vê em sua visão "alienada"? Transforma-o? Deforma-o? Não seria função da arte a mediação entre o mundo e os homens? Não seria sua função reler o mundo de uma forma outra, recriá-lo à sua maneira para nos permitir compreendê-lo melhor? (SILVA, 2020, p. 75).

A reflexão sobre esses problemas leva Edson a investigar outros conceitos capitais na obra de Malraux: "[s]em se afastar do mundo e sem deixar de refletir suas marcas históricas, a arte o ultrapassa e cria um mundo próprio, o que Malraux sabiamente chamou de "intemporal" ou de "surmonde" (SILVA, 2020, p. 75-76). É operando na tensão entre representação e criação que o conceito de intemporal, em conjunto com aquele de metamorfose, outro "conceito-chave da reflexão malruciana sobre a arte" (SILVA, 2020, p. 76), possibilita a Edson se apropriar do pensamento de Malraux para provocar suas inquietaçôes e performar sua própria sensibilidade crítica. Tal sensibilidade pode ser mais bem compreendida a partir de outro conceito que aparece no artigo supracitado, a saber, o de "antidestino" das artes. Ao abordar o tema da "ressurreição das obras" pelo permanente diálogo entre elas, Edson explica que

o antidestino da arte é, pois, sua metamorfose, sua presentificação. Não é nem uma garantia de vida eterna nem a perpetuidade da memória individual de 
um gênio. Não é função da arte resgatar o passado ou perenizá-lo tal qual. Sua função é transformá-lo, engendrando novas formas adequadas ao hic et nunc (SILVA, 2020, p. 82).

Pensando não apenas sobre Malraux, mas sobretudo com ele, os artigos de $A$ reflexão tecem um agenciamento singular de vozes que permitem a Edson estender, em conjunto com outros teóricos, críticos e escritores, essa atenção necessária às "formas adequadas ao hic et nunc" de seu próprio tempo. Como procurei argumentar, esse é o movimento que também comanda a segunda parte do livro, anunciando a resposta que seus escritos dáo à pergunta que se coloca ainda na introdução: "Ler Flaubert ainda é possível? E Proust, é compreensível? Ou Baudelaire, como perscrutá-lo?” (SILVA, 2020, p. 7). Pensar a literatura como antidestino é, como sugere o autor em diálogo com a imagem da teia proposta por Derrida - e que serve como epígrafe de $A$ reflexáo -, relançá-la nos jogos de sentidos mediados pelo leitor atento que Edson sempre foi:

cada leitura refaz o percurso daquela aranha que volta à teia e retoma os fios que não são seus, e os torna a tecer, para que se tornem novamente seus. Só assim compreendo a escritura e a releitura de textos - táo inacabados e indefiníveis, como toda teia em processo (SILVA, 2020, p. 8).

Como pesquisador e crítico, mas também como professor, Edson não nos deixa, na forma do presente livro, uma obra póstuma, mas sim o conjunto de fios de sua biblioteca imaginária, convidando-nos, assim, a participar da enorme tecelagem desse antidestino que ele, tão dedicadamente, ajudou a tecer. Pois, como o título sugere numa espécie de piscadela ao leitor, não se trata de uma reflexáo sobre, mas da literatura, cabendo a cada leitor a delicada tarefa de recompor essa teia.

\section{Referências}

BARTHES, Roland. O grão da voz. Tradução de Mario Laranjeira. São Paulo: Martins Fontes, 2004.

BENJAMIN, Walter. O conceito de crítica de arte do Romantismo alemão. Tradução de Márcio Seligmann-Silva. São Paulo: Iluminuras, 2002.

CAVALIERE, Arlete; ARAÚJO, Eduardo Tolentino. Apresentação. In: TCHÉKHOV, A.P. Ivánov. Tradução de Arlete Cavaliere e Eduardo Tolentino Araújo. São Paulo: Edusp, 2014.

DIDI-HUBERMAN, Georges. L'Album de l'art à l'époque du Musée imaginaire. Paris: Hazan \& Louvre éditions, 2013. 
MALRAUX, André. Le musée imaginaire. In: MALRAUX, André. Les voix du silence. Paris: Gallimard, 1951.

SELIGMANN-SILVA, Márcio. [Orelha do livro]. In: SILVA, Edson Rosa da. A reflexão da literatura: ensaios sobre literatura francesa. Belo Horizonte: Moinhos, 2020.

SILVA, Edson Rosa da. A reflexão da literatura: ensaios sobre literatura francesa. Belo Horizonte: Moinhos, 2020.

Rodrigo Ielpo é Professor de língua e literatura Francesa da Universidade Federal do Rio de Janeiro. Possui doutorado em regime de cotutela pela Universidade Federal do Rio de Janeiro e pela Universidade de Paris 7 (2010). Fez estágios de pós-doutorado na UNICAMP e na Universidade de Paris 7, ambos com bolsa FAPESP. É autor de diversos artigos em torno da literatura e do teatro contemporâneos em língua francesa e das relaçóes entre literatura e história envolvendo as literaturas francesa e brasileira contemporâneas.

E-mail: rodrigoielpo@letras.ufrj.br 